\title{
Special issue on selected results of the FORSEE project
}

The Rio summit in 1992 highlighted the global problems of forest degradation and destruction. In response, governmental and non-governmental agencies have adopted ecological, economic and socially acceptable forest management standards, and have developed methods to evaluate the conformity of practices to those standards and to assess the sustainability of forests using mutually agreed principles. Criteria of sustainable forest management have been established and indicators developed to monitor changes in valued forest system components. Reporting and monitoring of criteria and indicators is conducted at national level and many indicator values are derived from national forest inventories. However, there are still large differences between countries in criteria and more particularly in the indicators used to evaluate progress. It increasingly appears that the enforcement of forest management standards and the assessment of sustainable forest management criteria and indicators at various levels (international, national, regional ...) require further research and development in order to assist foresters, land-use planners and policymakers to adjust their practices and to facilitate societal dialogue on sustainable forest management. In particular, sustainability assessment at local levels (or meso-scales such as watersheds, landscapes, regional territories) offers the possibility of adapting forest management and improving forest operations through close interactions between socio-economic actors, local authorities and end-users linked to forest certification schemes.

The FORSEE project was initiated in 2003 in order to test and improve criteria and indicators for sustainable forest management at regional level in the Atlantic regions of Europe. Pilot zones, varying in size from hundreds to many thousands of hectares, were established in France (Aquitaine), Ireland (North-west), Spain (Euskadi, Galicia, Navarra and CastillaLeon) and Portugal (North and Central) with the objective of testing criteria and indicators of sustainable forest management. The criteria used were based on the pan-European ministerial process. Indicators were selected from existing processes (MCPFE, Montreal, etc.) or in some cases developed by expert groups, established for each criterion, within the project.

In addition to testing the criteria, specific scientific studies were carried out in each region in order to provide useful data which could, in the future, be used for the implementation of existing or newly developed indicators of sustainability.

The project was co-financed by the European Union (FEDER-INTERREG IIIB Atlantic Area) and supported by many administrative, management and educational organisations within the regions.

At the conclusion of the project, a conference on indicators for sustainable forest management was held in the Catholic
University, Porto, in December 2006. This special issue comprises a selection of the papers presented at that conference.

The paper by Diaz-Varela et al. presents an analysis of the use of several landscape indices using maps of different spatial resolution, concluding that a large majority of the landscape indicators tested can be used to analyse lowresolution maps with acceptable results. An interesting study dealing with the assessment of deadwood volumes has been provided by Teissier du Cros et al. (French National Forest Inventory) comparing precision/costs of fixed-area and lineintersect sampling for the assessment of stumps, standing and lying deadwood. The recommendation for national forest inventory is to use line-intersect for lying deadwood and fixedarea sampling to assess stumps and standing deadwood. Soil indicators were studied by Gartzia-Bengoetxea et al. in order to evaluate the use of several potential soil indicators in forests in the Basque Country under different types of management involving species change and heavily mechanized forest operations. The monitoring of biodiversity was the subject of several papers. Martínez et al., worked with carabid diversity in different forest types in Northern Spain. Mitxelena and Onaindia analysed the potential of pine plantations to restore native forests in a highly fragmented river basin and by Brin et al. used the species richness of saproxylic beetles in order to test "species" and "environmental" approaches to assess biodiversity in maritime pine. These latter authors studied the quantity of deadwood as a predictor of saproxylic beetle richness and found promising correlations between the two indicators. Understorey can contribute significantly to carbon stocks but usually it is not assessed in traditional inventories. Porté et al. developed models to estimate understorey biomass using vegetation cover measurements and to investigate upscaling methodologies from stand to regional level. Health monitoring was the subject of the paper by Martín-García et al. who proposed and studied the use of digital photos to accurately and objectively monitor crown condition in clonal poplar plantations.

The set of eight papers provide advance in the use of selected indicators of sustainable forest management and on the methods that must be used to assess them, thus providing guidance for the design of future monitoring schemes for sustainability assessment.

We are indebted to the many referees who reviewed the submitted manuscripts and offered helpful suggestions to the authors.

Margarida Tome, Ted Farrell, Editors of the special issue 